\title{
Design of A Fuel Storage Cask Using Cygas Code for Multi Layered Shielding Analysis
}

\author{
Fouad Abolaban \\ Department of Nuclear Engineering, Faculty of Engineering, King Abulaziz University, Jeddah, Saudi Arabia
}

\begin{abstract}
ABTRACT
A dry storage facility based on the concept of using the concrete canister has been suggested as a storage facility for a fuel assembly. The objective of this research was to perform a preliminary analysis for the design of dry storage of booster fuel. Criticality calculations performed by WIMSD-4 code indicated that booster fuel might become critical when placed in the fuel storage bay under light water. Shielding analysis for calculations of exact thickness of transfer flask and concrete required the gamma spectrum, which was being emitting from the booster rods due the buildup of radioactive fission products in the booster fuel. ORIGEN computer code performed the calculations for the prediction of fission product compositions, multigroup gamma release rate as well as the thermal decay heat in the booster fuel as a function of bum up and cooling time. The proposed dry storage canister would have $90 \mathrm{~cm}$ thick concrete walls with $15 \mathrm{~cm}$ thick lead lining inside. Storage flasks each containing a fuel assembly will be arranged in square array in the cylindrical concrete canister. Shielding analysis performed by CYGAS computer code showed that a thickness of few centimeters for lead transfer flask and 90 ern of concrete is enough for the design of dry storage. Validation of the CYGAS analysis has been performed by multilayer calculations. Lead transfer flask having wall thickness of $15 \mathrm{~cm}$ will be used to transfer the storage flasks to the concrete canister.
\end{abstract}

Keywords: Shielding analysis, fuel assembly, ORIGEN Code, exposure rate, CYGAS code, shielding thickness DOI: $10.7176 / \mathrm{JETP} / 9-6-05$

Publication date: August $31^{\text {st }} 2019$

\section{INTRODUCTION}

Dry storage for spent fuel is considered as a viable option for long term fuel storage. to ensure that the A number of techniques are being considered in developed countries for long term fuel storage are like in the U.S., Canada, and Western Europe [1]. In the dry well concept the major design variables which are incorporated are decay heat load, soil conductivity, the hole spacing, and the hole diameter [2]. The Air-Cooled Vault concept is used to reduce the radiation shielding and physical protection requirements [3]. For the deisgn of fuel CASK the major considerations are as follows:

Decay Heat: After a certain period of cooling in wet storage pool, the decay heat of spent fuel is reduced to a considerable value which is to be determined using a suitable code.

Fuel Composition: Fuel composition includes enrichment of fissile and non-fissile material, cladding material etc.

Fission and Activation Products: The spent fuel contains actinides, fission products and other radioactive nuclides which are the major source of decay heat and radiation. Their activity is to be determined to provide for the shielding and safety analysis.

Geometry of Fuel assemblies:

The geometry and shape of fuel assemblies (cylindrical or spherical) is an important parameter in the design of casks. The heat transfer phenomenon is heavily dependent on the geometry of the fuel assemblies.

\section{Arrangement of Fuel elements:}

The arrangement of fuel elements in a fuel assembly is a major concern in the design of cask. The cask physical layout is evaluated in the perspective of fuel elements arrangement. Heat transfer models and shielding design greatly vary with the arrangement of fuel elements. 
Environmental conditions:

The design of cask should be compatible with the environmental conditions (wind velocity, humidity, temperature etc.). The geological factors are to be considered which include natural disasters like earthquakes, storms etc.

\section{Radiation shielding:}

The design of casks is done to minimize the external radiation fields that should not exceed the acceptable criteria. Loading and unloading of spent fuel into casks is done using equipment and methods designed in accordance with the ALARA principle.

DESIGN STEPS FOR SPENT FUEL CASKThe Booster Fuel Assemblies usually contains enriched Aluminum Uranide fuel. The boosters may serve top provide a sufficient excess reactivity to bring the reactor back to maximum power within thirty minutes after trip from full power. It also allow load cycling by compensating for Xenon transients and provide reactivity to continue reactor operation if the fueling machine is out of order. When the booster has been used for any significant period, cooling must be provided to remove the decay heat. Cooling of the booster fuel assembly cannot terminated whether the reactor is operating or in shutdown state. If the cooling mechanism fails to operate, temperature would rapidly increase and there is a possibility of deformation of the booster assembly and finally a meltdown of booster fuel

\section{Shielding Analysis:}

First of all the for the source terms is done using a number of codes such as ORIGEN2.1, MCNP, QAD, DORT, SCALE, etc $[5,6]$. This give us the requirements for shielding to be provided

\section{Decay Heat Analysis:}

In the first step, decay heat of spent fuel after it has been cooled for a certain period of time in the wet storage pool, is calculated for a fuel bundle. This determined heat load is then used in further calculations.

\section{Criticality Analysis:}

The multiplication factor has been calculated using WIMS-D/4. It generates the necessary group constants for the homogenized cell. Also CITATION code is used to determine the the infinite multiplication. SCALE 4.4 can determine the nuclide composition calculation with the core and the keff calculation $[7,8]$.

The best worldwide summary of light water reactor-related temperature limit determination for inert dry storage of spent fuel assemblies was published by EPRI [9]. The inner shell is usually of forged carbon steel or stainless steel material. It is provided as a containment barrier for fission products. It also serves as a shielding material against gamma and neutrons as well as it helps in the removal of decay heat from the spent fuel. It also provides the structural support to the spent fuel assemblies. 


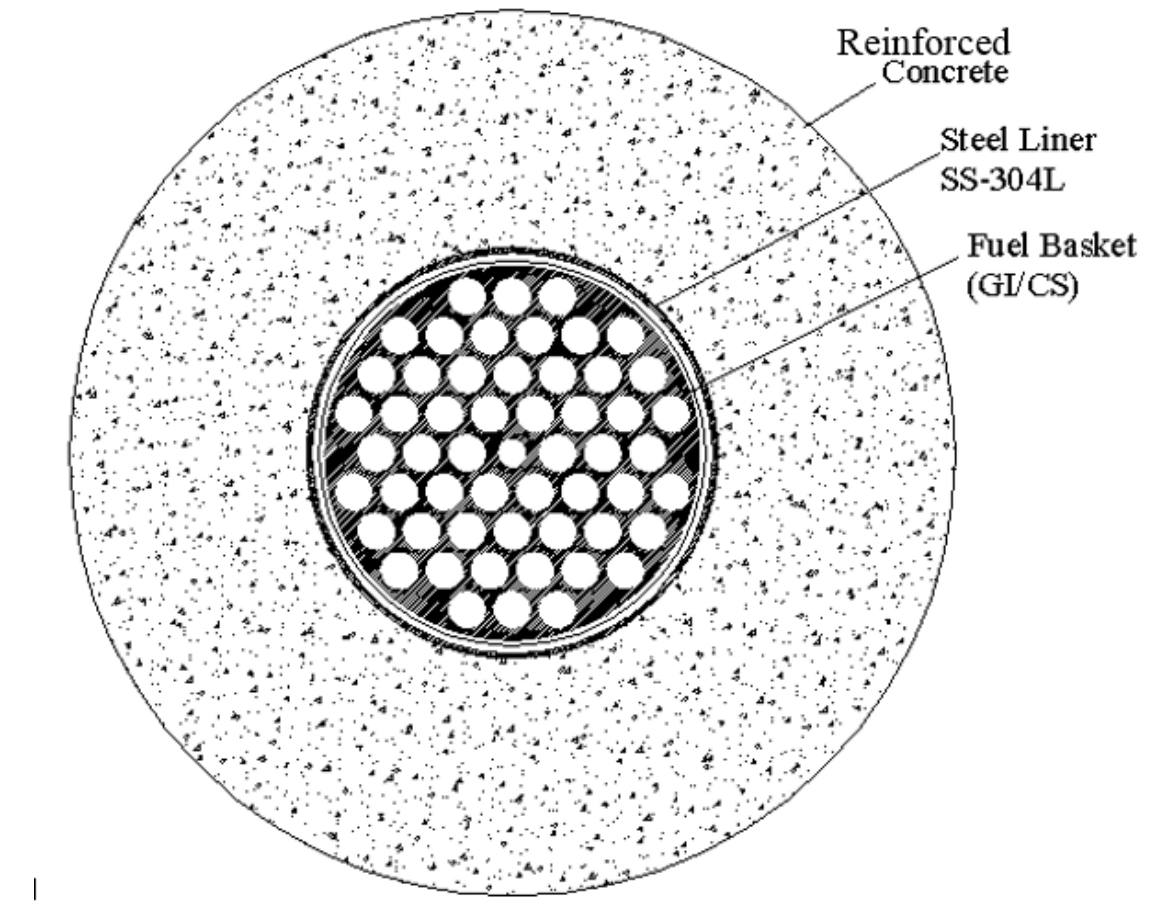

Figure1 General layout of the proposed cask

There are two types of shielding materials required: one for the fast neutrons and the other for gamma radiations. Fast neutrons are highly energetic particles and give a large dose in a little exposure. So, their shielding is of major concern. Gamma rays are highly penetrating radiations and can not be stopped completely but can be attenuated to a safe limit. Thus, there are two types of shields used in a cask; neutron shield and gamma shield. Concrete is the most widely used neutron shield. Usually, reinforced concrete is used to give structural strength to the cask and provide for the time-dependent degradation. Stainless steel is also used as a neutron shield but it faces a problem of "neutron streaming". Hydrogenous materials like water is very efficient in the shielding of fast neutrons. It slows down the neutrons and the boron present in it absorbs these neutrons. Lead is mostly used for the shielding of highly energetic gamma rays. Concrete is also very much effective in the shielding of gamma rays.

\section{MATERIALS AND METHODS}

ORIGEN computer code is being used for calculating the fission product inventory in the core and discharged fuel as a function of irradiation as well cooling time. It is a versatile point depletion code that solves the equations of radioactive growth and decay for large number of isotopes. ORIGEN computer code is a collection of programs that processes a library of nuclear properties to construct first order, linear ordinary differential equations describing the rate of formation and destruction of the nuclides contained in the library. It solves the resulting equations for a given set of initial conditions and irradiation history to obtain isotopic compositions of the discharged fuel as a function of post irradiation time; and uses the isotopic compositions and nuclear properties of individual nuclides to obtain the radio-activities, thermal power, potential hazards, ingestion hazards, and neutron production rates in the discharged fuel. An extensive nuclear data library in ORIGEN code contains six data files; three of them are related to the data on decay schemes and neutron absorption cross sections for more than eight hundred isotopic and the remaining three give the data related to the multigroup gamma production rates that result from the radioactive decay of these nuclides. The multigroup photon yield data for the cladding and structural materials heavy metal isotopes and fission product isotopes is contained in last three data files of the ORIGEN nuclear data library $[10,11]$. These data files contain twelve energy groups as given in following : 
Table 1 Energy distribution in the ORIGEN data files

\begin{tabular}{|c|c|}
\hline Energy Group & Mean Energy (MW) \\
\hline 1 & 0.30 \\
\hline 2 & 0.63 \\
\hline 3 & 1.10 \\
\hline 4 & 1.35 \\
\hline 5 & 1.99 \\
\hline 6 & 2.38 \\
\hline 7 & 2.75 \\
\hline 8 & 3.25 \\
\hline 9 & 3.70 \\
\hline 10 & 4.22 \\
\hline 11 & 4.70 \\
\hline 12 & 5.25 \\
\hline
\end{tabular}

The output file of ORIGEN computer code contains isotopic compositions of fuel as a function of irradiation time, arranged in tables. It also contains the tables, describing the radio activities, thermal power, potential inhalation and ingestion hazards and neutron production rates in the irradiated or discharged fuel. Besides these results, ORIGEN also generates twelve-group photon energy spectrum as a function of time for fission products. In order to perform calculations for booster fuel assembly shielding, this multi group gamma energy spectrum is of vital importance. From this table it is clear that out of twelve energy groups only eight groups of gamma energy are to be selected for shielding analysis, because gamma sources of high energy have been decayed, as they had short half-lives.

The proposed design of the dry storage for the fuel assembly would consist of a concrete canister in a passive cooling system. It would be a hollow, reinforced concrete cylinder constructed in a vertical position on a concrete pad. After removal from its parking position in the core, booster fuel assembly can be packed in the storage flasks. Each storage flask consists of one booster fuel rod and is being stored in the fuel storage bay temporarily. Exact thickness has been calculated through CYGAS shielding analysis and WIMSD-4 criticality calculations. The design criterion for storage flask is to select a material and its thickness so that the booster may not become critical, when placed in the fuel storage bay.

\section{RESULTS AND DISCUSSIONS}

CYGAS computes the gamma ray flux distribution in a multilayered shield surrounding a cylindrical source of finite length, assuming infinite slab shields in the direction of the cylindrical axis and coaxial infinite cylindrical shields in radial direction [12].

CYGAS code has the following features:

- In axial direction the flux can be calculated along the axis of the cylinder only, while there is no restriction on the $(\mathrm{r}, \mathrm{z})$ coordinates for the radial flux routine.

- Flux in axial direction is calculated by dividing the cylindrical source in disc sources. The resulting dose is calculated by summing the contribution from each disc source.

- Flux in radial direction is calculated by dividing the source in line sources. The resulting dose is calculated by integrating contribution from each line source.

- Cylindrical source can be divided in maximum 999 disc or line sources. 
- Build-up of gamma radiation in shield and source is represented by Taylor formula for a homogenized shield, which is included in the disk and line source kernels.

The effects of heterogeneity in multilayered shield is estimated by calculating the self shielding distance of the cylinder for an equivalent point source and by determining the ratio of the buildup factor calculated with an empirical heterogeneous shield formula and with the Taylor formula for the homogenized equivalent source. This ratio can be calculated for point source on shield region interfaces for the correction of usual capture gamma calculations using a homogeneous material buildup factor. For calculations in radial direction, source is divided into a number of line sources and the flux in calculated by integrating the contribution from individual line source. Relation used for each line source is given as under: The proposed design is a cylindrical reinforced concrete shell with a capacity to store sealed fuel baskets, each containing spent fuel bundles. In this design, the atmosphere in the storage basket is air. Fuel bundles are stored in staggered arrangement in the fuel basket. The fuel bundles are held in position by two fixed perforated plates. The basket is perfectly sealed to prevent any releases of radioactive material. For all the three case described above, exposure rates have been calculated for various thicknesses and are plotted to obtain the required material thickness against the allowable dose. The results have also been validated with manual calculations. Input files for all the three case have been prepared by taking into account the contribution

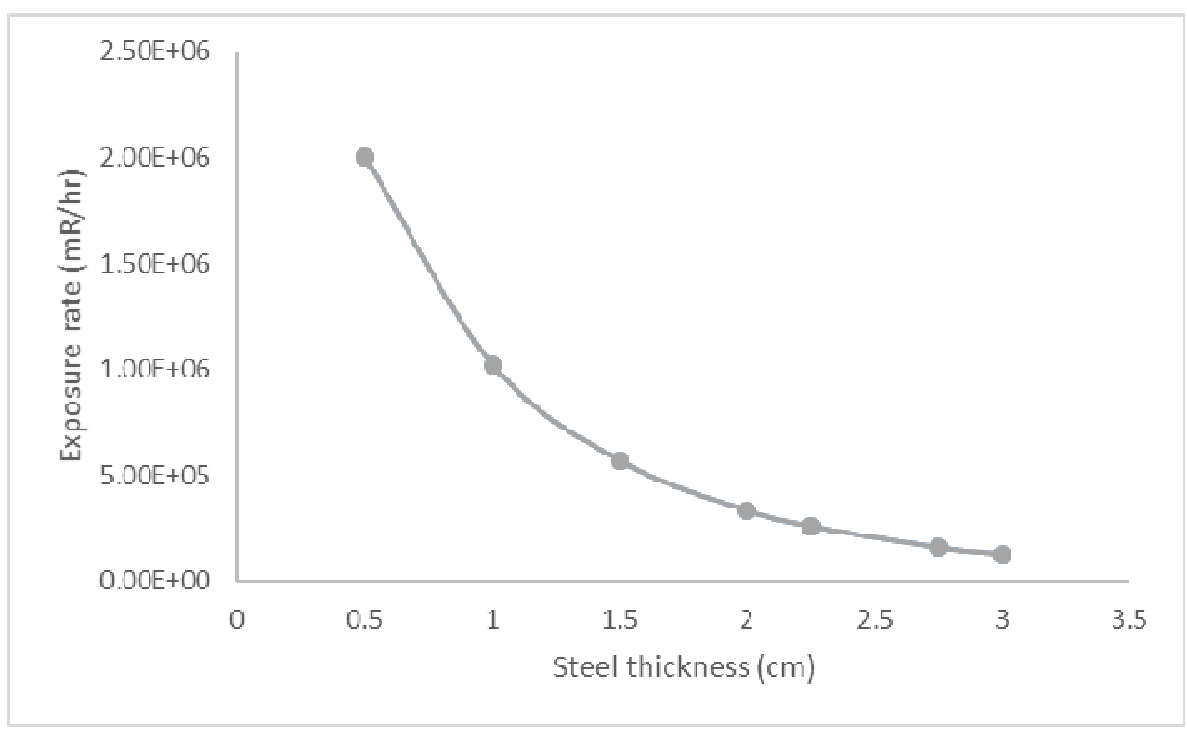

Figure 2: Exposure rate at the contact surface for steel shield

From shielding point of view, the high temperatures at the internal concrete wall result in tensile stresses on the outside surface, which can result in surface cracking. It is to be noted that temperature rise in vertical direction is more than that in radial direction [13]. 


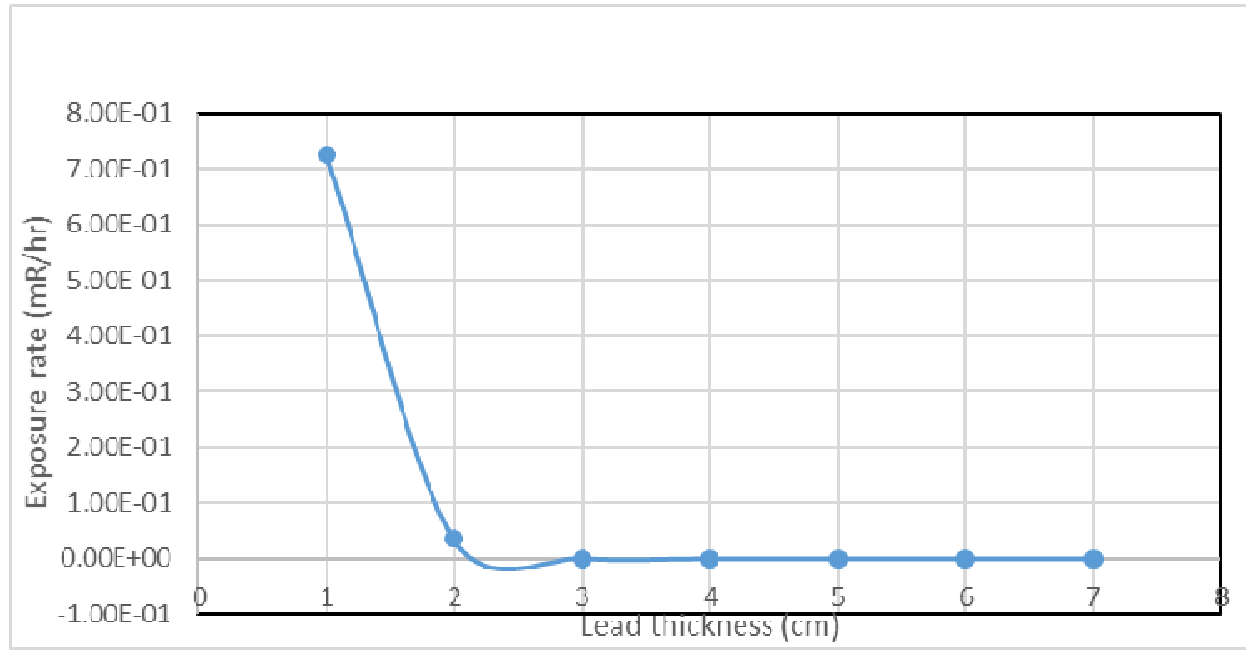

Figure 3: Exposure rate at the contact surface for lead shield

This is due to the fact that heat transfer is considered only in vertical direction in the top lid of the cask while radial heat transfer is neglected. Hence, the temperature at the top of the basket is sufficiently higher than that at the wall. If radial heat transfer is considered in the top lid of the cask, then the average temperature of the top cover of the fuel basket would be around $125^{\circ} \mathrm{C}$. For the multi Layered Shielding Analysis, the source term has been considered as line source and relations for calculations of dose are defined as follows: For shielding calculations, it is assumed that cladding provides no gamma attenuation and the shielding is exposed equally from all booster elements.

For a Disc Source

$$
\begin{gathered}
\sigma_{b}=\frac{5}{2} \sum_{n=1}^{2} A_{n} E_{n}\left[\left(1+\alpha_{n}\right) \mu \alpha\right] \\
E_{n}(x)=x^{n-1} \int_{x}^{n} \frac{e^{-t}}{t^{n}} d t \text {, where } t=\mu
\end{gathered}
$$

The following parameters are used for calculations:

Gamma Energy $=\mathrm{E}=0.63 \mathrm{Mev}$

Incident flux $=\varphi_{\mathrm{o}}=1.9 \times 10^{8} \gamma / \mathrm{cm}^{2} . \mathrm{sec}$

Radius of cylindrical source $=\mathrm{R}=0.80 \mathrm{~cm}$

Steel shield thickness $=\mathrm{a}_{1}=6 \mathrm{~cm}$

Concrete shield thickness $=\mathrm{a}_{2}=11 \mathrm{~cm}$

Taylor's coefficient of concrete $=\mathrm{A}=25.007$

$\alpha_{1}=-0.13$

$\alpha_{2}=-0.09$

Linear attenuation coefficient $($ source $)=\mu_{\mathrm{s}}=0.40 \mathrm{~cm}^{-1}$

Linear attenuation coefficient (steel) $=\mu_{\mathrm{st}}=0.60 \mathrm{~cm}^{-1}$

Linear attenuation coefficient $($ concrete $)=\mu_{\mathrm{c}}=0.19 \mathrm{~cm}^{-1}$

Build up flux at concrete shield contact point is geven by

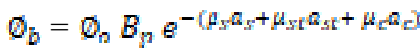

Where $\mathrm{B}_{\mathrm{p}}$ is called Taylor's buil; $\mathrm{d}$ up factor and is given by

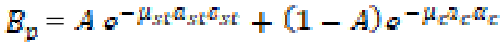


$B_{p}=3.90$

The value of calculated build flux by manual work and CYGAS code are $2.32 \times 10^{6} \mathrm{\gamma} / \mathrm{cm}^{2}$. sec and $2.46 \times 10^{6}$ $\gamma / \mathrm{cm}^{2}$. sec respectively.

$\mathrm{X}_{1}=\left(1+\alpha_{1}\right) \mu a=6.9$

$\mathrm{X}_{2}=\left(1+\alpha_{2}\right) \mu a=9.1$

$\theta_{1}=\theta_{2}=80^{\circ}$

Build up flux is found from the following [11]:

$$
\sigma_{\mathrm{b}}=\frac{5}{4 \pi R} \sum_{n=1}^{2} A_{n}\left[F\left[A_{1}, \quad\left(1+\alpha_{n}\right) \mu R\right]+\left[A_{2}, \quad\left(1+\alpha_{n}\right)_{\mu} R\right]\right]
$$

Using Sievert integral functions, the buildup flux is found to be

$\phi_{b}=1.7 \times 10^{10} \frac{\gamma}{\mathrm{mm}^{2} \sec }$

Similarly the build up flux for other energy groups are as follows:

Table 2: Build up flux at various energy levels

\begin{tabular}{|l|l|l|}
\hline Energy (Mev) & $\begin{array}{l}\text { Source Strength } \\
\gamma / \mathrm{cm} . \mathrm{sec}\end{array}$ & $\begin{array}{l}\text { Build up flux } \gamma / \mathrm{cm}^{2} . \\
\text { sec }\end{array}$ \\
\hline 0.63 & $1.60 \mathrm{E}+10$ & $1.66 \mathrm{E}+05$ \\
\hline 1.15 & $4.38 \mathrm{E}+7$ & $9.03 \mathrm{E}+03$ \\
\hline 1.60 & $4.25 \mathrm{E}+6$ & $3.54 \mathrm{E}+03$ \\
\hline 2.05 & $1.07 \mathrm{E}+6$ & $1.17 \mathrm{E}+02$ \\
\hline 2.45 & $9.01 \mathrm{E}+4$ & $4.65 \mathrm{E}+01$ \\
\hline 2.80 & $6.53 \mathrm{E}+3$ & $5.58 \mathrm{E}+00$ \\
\hline 3.30 & $2.14 \mathrm{E}+2$ & $1.35 \mathrm{E}-01$ \\
\hline
\end{tabular}

Shielding of the booster fuel assembly should provide radiation protection to workers and the public in accordance with the requirements and principles described by International Commission on Radiation Protection (ICRP) and ALARA principle must be followed [14]. Main features of ALARA principle are:

- $\quad$ No practice shall be adopted unless its introduction produces a net benefit.

- All exposures shall be kept As Low As Reasonably Achievable, economic and social factors being taken into account

The effective dose to individuals shall not exceed limits recommended by the ICRP commission, as given in Table 2 
Table 3: Recommended dose limits from ICRP

\begin{tabular}{|c|c|c|c|}
\hline & $\mathrm{mSv} / \mathrm{yr}$ & $\mathrm{mRem} / \mathrm{hr}$ & $\mathrm{mR} / \mathrm{hr}$ \\
\hline Worker & 20 & 1.0 & 1.08 \\
\hline Public & 1.0 & $1.14 \mathrm{E}-02$ & $1.22 \mathrm{E}-02$ \\
\hline
\end{tabular}

While considering the optimum design of the dry storage for the booster fuel assemblies three cases have been considered.

- To design eight transfer flasks each containing a storage flask sealed 111 it and storing these eight transfer flasks in the concrete canister.

- To design a single transfer flask containing eight storage flasks and storing this transfer flask in the concrete canister.

- To design only one transfer flask containing single storage flask for carrying it towards the dry storage and storing the storage flasks in the reinforced concrete canister having 15 ern thick lead lining inside it.

First and second cases are more attractive if the dry storage facility has to be located far away from the plant because in this way it could be transported easily without any danger of radiation exposure. Since it is more probable to store the booster fuel near the waste disposal area then third case in which it has been proposed to design a single transfer flask containing only one storage flask and ultimately storing the storage flasks in concrete canister having lead lining shall be considered as it is more economical.

\section{CONCLUSIONS}

The objective of this research was to perform a preliminary analysis for the design of dry storage of booster fuel. Criticality calculations performed by WIMSD-4 code indicated that booster fuel might become critical when placed in the fuel storage bay under light water. Shielding analysis for calculations of exact thickness of transfer flask and concrete required the gamma spectrum which was being emitting from the booster rods due the buildup of radioactive fission products in the booster fuel. ORIGEN computer code performed the calculations for the prediction of fission product compositions, multigroup gamma release rate as well as the thermal decay heat in the booster fuel as a function of bum up and cooling time. Design criterion for the transfer flask and the concrete has been considered such hat dose rate at their contact surfaces should be under limits for worker and public respectively as prescribed by International Commission on Radiation Protection. Shielding analysis performed by CYGAS computer code showed that a thickness of few centimeters for lead transfer flask and 90 ern of concrete is enough for the design of dry storage. Validation of the CYGAS analysis has been performed by multilayer calculations. It has been proposed that the dry storage canister for booster fuel should be located in the waste disposal area, near the site approved by the General Manager

\section{REFERENCES}

1. Anttila, M. 1996, Gamma and neutron dose rates on the outer surface of the nuclear waste disposal canisters, Posiva-96-10.

2. Anttila, M. 1998, Radiation protection calculations for an encapsulation plant, Working

Report 98-81. 
3. Anttila, M. 2005, Radioactive Characteristics of the Spent Fuel of the Finnish Nuclear Power Plants, Posiva Working Report 2005-71.

4. Bell, Z. W. 1995, Evaluation of photoneutron production at high energy linacs, Oak Ridge Y-12 Plant Report Y/DW-1367.

5. IAEA, 2000, Handbook on photonuclear data for applications, IAEA-TECDOC-1178. ICRP, 1996, Annals of the ICRP, Conversion Coefficients for use in Radiological

6. Protection against External Radiation, ICRP Publication 74, Volume 26 No. 3/4, 1996.

7. Kirkkomäki, T \& Raiko, H. 2005. Canister Transfer in Access Tunnel: Lay-out, system and operation description. Posiva Working Report 2005-54. (in Finnish)

8. Müller, Ch. et al. 2006, Reliability of non-destructive testing (NDT) of the copper canister seal weld. SKB report R-06-08.

9. Ranta-Aho, A. 2008, Review of the Radiation Protection Calculations for the Encapsulation Plant, Posiva Working Report 2008-63.

10. Ronnetag, U. et al, 2006. Reliability in sealing of canister for spent nuclear fuel. SKB report R-06-26.

11. Salo, J-P. 1997, Arvio säteilytasoista käytetyn polttoaineen loppusijoituskapselin kuljetussuojan ulkopuolella, Muistio KH-M-65-97, Posiva Oy. (in Finnish)

12. Sandelin, S. 2010, X-ray inspection setups for the disposal canister lid weld. Posiva Working Report 2009-98.

13. Varian Medical Systems, 2007. Varian Linatron High-Energy X-ray Applications. http://www.os.varian.com/media/security_and_inspection/resources/technical_informati on/pdf/LinatronAppManual7.pdf

14.Würz, H. A simple nondestructive measurement system for spent-fuel management. Nuclear Technology, Vol.95, pp. 193-206. 